\title{
THE NEW SUBJECT INDEX FOR THE NSW PUBLIC HEALTH BULLETIN
}

Jeanne B. Rudd

Indexer

D. Lynne Madden, Megan E. Black

and Carlie-Jane Naylor

NSW Public Health Bulletin Editorial Team

NSW Department of Health

\section{ABSTRACT}

This article describes the rationale and methods for reindexing all 17 years of the NSW Public Health Bulletin. The Bulletin is a valuable resource for researchers, however over time the subject index had become cumbersome with long lists of articles under broad headings. To facilitate searching the index was revised to include narrower terms, sub-headed terms, more cross-references and new terms reflecting changes in public health practice. Regular reports and surveys now have their own subject headings, and greater recognition has been given to public health history and organisations. The index appears annually in printed form. The full cumulated index is available online and in 2007 will be updated with each issue.

This article introduces the new subject index for the NSW Public Health Bulletin, a copy of which is included in this issue. The new index covers all issues of the Bulletin from the first, in May 1990, through to November-December 2006. It supersedes the previously published and annually updated subject index. The online version of the index is the same as the printed version; however, it will be updated with each new issue of the Bulletin. It is currently available at www.health.nsw.gov. au/public-health/phb/phb.html. This article describes the changes within the new subject index and the rationale behind these changes. It also describes improvements that have been made to the on-line index.

In the first issue of the Bulletin George Rubin and Stephen Leeder defined public health as 'an organised societal effort to protect, promote and restore health. It is a combination of science, skills and beliefs directed to the maintenance and improvement of health through collective or social actions. The programs, services and institutions involved emphasise the prevention of disease and the health needs of the population'. ${ }^{1}$ Further, they defined epidemiology as 'the study of the distribution and determinants of health-related states or events in specified populations and the application of this study to control health problems-it is the scientific discipline underpinning public health practice'. ${ }^{1}$

From its inception, the NSW Public Health Bulletin has reflected these definitions in its coverage of diverse public health problems and the broad range of programs and systems devised to record, investigate and manage them, in particular from a NSW perspective. The revision of the index gives readers of the Bulletin greater access to this content and provides future researchers with a valuable guide to the ongoing development of public health as a discipline.

\section{REVISING THE INDEX}

Indexes are information retrieval devices designed to help readers identify potentially useful information and direct them to it efficiently. ${ }^{2}$ The cumulative indexes of journals are continually extended over time and are by nature very long. As journals grow and change, so too must their indexes, both in terminology and format. ${ }^{3}$

The broad single word subject headings used in the old-style Bulletin subject index contained a growing list of articles under each heading, making it difficult for readers to choose easily among the articles and identify specific content areas. In addition, for historical reasons, some sections of the Bulletin such as the Communicable Diseases Report were indexed by title rather than content area. To date, if researchers have been interested in historical records of communicable disease outbreaks in NSW, a manual search of the Communicable Diseases Report was required.

To improve usability, in particular to reduce search times for the reader, the subject headings needed to be more specific. A number of standard approaches ${ }^{2,3}$ were taken including: using narrower single terms; using subheadings within single terms; adding new terms that reflect changes in public health practice; and ensuring that regular reports and surveys have their own headings. The new features of the index are reported below.

\section{NEW FEATURES OF THE INDEX}

\section{Narrower single terms}

Using single terms that cover narrower content areas assists the reader to easily locate specific articles. For example, hepatitis now appears as six subject headings: hepatitis, hepatitis A, hepatitis B, hepatitis C, hepatitis D and hepatitis $\mathrm{E}$ - where only those articles that refer to hepatitis in general are listed under the heading 'hepatitis'. The index now also includes the rarer viruses such as Kunjin or Sindbis viruses, which are mentioned in papers referring to vector-borne viruses but which were not previously indexed.

\section{Use of subheadings}

Another way to increase specificity is to include subheadings to narrow the searches. The following subjects previously had long undifferentiated lists of articles: Aboriginal Australians, children, drug use, health promotion, HIV infections, immunisation, notifications, rural health, and surveys. These are now listed under more specific subheadings, for example some of the new subheadings for 
children are: children-cancer, children-early childhood intervention, children-lead poisoning, children-obesity.

\section{New headings}

Public health practice has changed over the lifetime of the Bulletin and these changes are reflected in some new headings. These are: adverse events after immunisation, adverse reactions, advocacy, disease management, geocoding, health impact assessment, health planning, health policy, information technology, life expectancy, mental health services, older people, outbreaks in institutions, performance indicators, population health, risk assessment, self-rated health, sewage disposal, social capital, trust, workforce development. In addition, new conditions of public interest such as avian influenza now have their own direct heading.

The heading 'Australia' has been added to the index to show federal or federal-state initiatives, whereas the heading 'New South Wales' has been removed as almost all articles concern state activities.

The index now also includes names of important public health organisations, programs or data collections that are mentioned in articles, such as the Centre for Health Economics Research and Evaluation (CHERE) and the Notifiable Diseases Database (NDD). Similarly, the names of people who have been leaders in the history of public health have now been included, for example, John Ashburton Thompson, who confirmed the role of the rat flea in the bubonic plague epidemic in Sydney in 1900. There is also a heading 'history of public health' to bring together all articles that include appropriate material.

Articles that refer to reports or surveys of the NSW Department of Health, such as the Report of the Chief Health Officer or the New South Wales Mothers and Babies Report, now have their own headings. Regular reports from within the Bulletin, such as the quarterly report of the Australian Childhood Immunisation Register or the HIV surveillance report also have their own headings.

\section{INDEXING COMMUNICABLE DISEASES}

A number of changes have taken place to improve the indexing of communicable diseases. The heading 'infectious diseases' has been replaced with 'communicable diseases', in line with current terminology in the Bulletin. This entry has then been divided into: 'communicable diseases-reporting' for regular reports which appear in each issue; and 'communicable diseases-control' for articles about disease control programs. Short articles and reports contained within the Communicable Diseases Reports are now indexed, as well as the regular reports as mentioned above. The inclusion of a new heading 'notifiable diseases reporting system' brings together all the changes to the lists of notifiable conditions and related data collection practices.

\section{IMPROVED CONSISTENCY IN SUBJECT HEADINGS}

There were several inconsistencies in terminology within the index, many of which related to changes over time. The regular state health surveys have changed their titles over the years, making it difficult for the reader to locate specific articles. Articles on all past and present surveys are now listed under the current title 'New South Wales Population Health Survey' with subheadings for the Adult, Child and Older People surveys. In addition, where possible, the vocabulary of the subject headings was matched to those of the NSW Department of Health Thesaurus, ${ }^{4}$ ensuring consistency across health organisations and between indexers.

\section{LENGTH OF THE INDEX}

The addition of new and more specific headings, and the more thorough indexing of some items, has inevitably lengthened the index. It is not difficult to navigate a lengthy online index but there are logical limits to the size of a printed index. In order to allow the two forms of the index to be identical, multiple entries were limited as much as possible and more cross-references were added, showing linkages between subjects, rather than citing articles under multiple subject headings. For example the New South Wales Mothers and Babies Report includes information on a large number of topics such as preterm birth, caesarean sections, birth defects, premature birth, pregnancy, maternal mortality, infant mortality, and stillbirths. Rather than repeating the reference to the report under each of these headings, a 'see' reference is inserted from these headings to the report's main entry.

\section{THE ON-LINE INDEX}

The on-line index is identical to the printed index; however, to increase the usefulness of the on-line index a number of changes have been made. Firstly the online index will now be updated with each new issue of the Bulletin (as of 2007), instead of annually. Secondly, the addition of many more cross-references within the index enables readers to move quickly between cross-referenced subjects, as they are electronically linked. Thirdly, for articles that relate to specific internet sites there are direct links from the index to the websites cited, for example, the CIAP (Clinical Information Access Program) website, or the NSW Health Capacity Building website. These articles are invariably indexed under 'internet'.

\section{A CONCLUDING PARAGRAPH FROM THE INDEXER}

The revision of the index has been a major project. In the 17 years of the Bulletin there have been 158 issues comprising over 2,800 pages. As indexer I have been very impressed with the wide scope of subject areas but also 
concerned by some of the possible conditions such as ciguatera poisoning and Ebola. I have a ridiculous image of saluting poultry whenever I see the term 'sentinel chicken' and I now observe the following life rules: Wash your hands. Look after your teeth. Don't smoke. Do socialise. Avoid mosquitoes and under-cooked chicken. For me, two of the most startling facts presented in the Bulletin are: the 1919 influenza pandemic infected 36 per cent of Sydney's population, eventually killing over 6000 people in NSW; and more people in NSW now die from suicide than from road injury. Can I suggest that you use the index to find these and other enlightening articles.

\section{A CONCLUDING PARAGRAPH FROM THE BULLETIN EDITORIAL TEAM}

The task of preparing an index is a time consuming job if taken seriously. While software is available for compiling the data and formatting the final product, a human being is required for making decisions about the main themes of an article and the content to be included in the index. If a computer created the entire index it wouldn't be a good one! The revision of the Bulletin index involved considerable input from a variety of people in addition to the indexer and the editorial team, including public health practitioners and researchers, regular readers of the Bulletin and a librarian. We hope you find the revised version efficient and simple to use.

The printed version of the index will be updated annually and published with the last issue of the Bulletin for each year. The online version of the index will be updated with each issue and is currently available at: www.health.nsw.gov.au/public-health/ phb/phb.html.

\section{REFERENCES}

1. Rubin G, Leeder S. Improved public health. $N S W$ Public Health Bull 1990; 1(1-5): 2,6.

2. Commonwealth of Australia. Style Manual: For authors, editors and printers (6th edition). Canberra: John Wiley and Sons Australia Ltd, 2002.

3. Weaver C. The gist of journal indexing. Keywords 2002; 10(1): $16-22$.

4. NSW Department of Health. NSW Health Thesaurus [MS Excel], last updated 20 July 2006. Sydney: NSW Department of Health, 2006. 욤 